\title{
Introducing Greek Conversation Analysis
}

\author{
Alexandra Vasilopoulou ${ }^{a}$, Chryso Hadjidemetriou ${ }^{\mathrm{b}}$, \\ and Marina Terkourafic

 \\ avasil@ecd.uoa.gr \\ ${ }^{b}$ University of Essex \\ chadji@essex.ac.uk \\ c)University of Illinois at Urbana-Champaign \\ mt217@illinois.edu
}

\begin{abstract}
Although conversation analysis (CA) has been widely employed in different languages, its application to Greek talk-in-interaction is still quite limited. For this reason, in our introduction we summarise briefly the foundations of CA and present international and Greek CA bibliography on different areas of analysis in a manner that will be accessible to conversation analysts of various interests but also to researchers who are new to the field. We begin by outlining the foundations of CA and then offer a brief background to its development and its relationship to other disciplines. The empirical basis of CA is stressed by focussing on the process of collecting and transcribing data for $\mathrm{CA}$ and the method and units of analysis. We also give background information on the main CA areas of analysis (grammar-and-interaction, prosody, narrative analysis, institutional interaction, feminist $\mathrm{CA}$, membership categorisation analysis, multimodal interaction). Finally, we present a brief overview of past studies of Greek talk-in-interaction and conclude with a summary of the articles of the Special Issue. By placing the emphasis on the fine-grained, turn-by-turn analysis, its ethnomethodological underpinnings and the understanding of social action, our aim is to set the tone for this Special Issue and to encourage future study of Greek conversational data and cross-cultural comparisons.
\end{abstract}

\section{Keywords}

talk-in-interaction, ethnomethodology, recordings, accountability, Harvey Sacks, Emmanuel Schegloff

\section{Why a special issue on Greek Conversation Analysis?}

The goal of this special issue is to introduce readers of the Journal of Greek Linguistics to a relatively un(der)explored area in the study of the Greek language: Greek Conversation Analysis. Conversation Analysis (henceforth CA) approaches everyday talk-in-interaction as a highly organised phenomenon. Through detailed and systematic analysis of transcripts of naturally occurring 
talk-in-interaction and working from the premise 'order at all points', conversation analysts aim to understand how participants produce and manage talk in order to communicate with one another. The methodological strengths of CA rest on three main premises: technologically sophisticated procedures of data collection involving audio and video recordings; systematicity of transcription, description, and analysis of the data; and the principle that analysis of talk should reflect the accountability, actions and orientations of the participants themselves rather than the preconceptions of the analyst.

Conversation analysis was initiated in the mid-1960s in North America by Harvey Sacks and his colleagues at UCLA, Emanuel Schegloff and Gail Jefferson (Sacks, Schegloff and Jefferson, 1974; Schegloff, Jefferson and Sacks, 1977; Sacks, 1992). Enabled by the technological advances of his time (i.e. the availability of audio recordings), Sacks began to address for the first time in the study of language and interaction the question 'why that now?', i.e., why specific things are uttered at particular sequential points in talk (Schegloff and Sacks, 1973: 299). ${ }^{1}$ This same question guides the work of the contributors to this special issue. After his unanticipated death in 1975, Sacks's colleagues and students continued and expanded his work, shaping a core CA agenda for the study of naturally occurring talk in different contexts. Today, CA is considered an empirical programme of a cumulative nature: research findings are subject to continuous examination and expansion in large conversational corpora in different languages. Besides work done on English, CA is an established area of research for many languages (see, e.g., Sorjonen, 1996, for Finnish;Tanaka, 1999, and Hayashi, 2003, for Japanese; Kim, 1999, for Korean; Mondada, 1995, and Chevalier, 2008, for French; Egbert, 1996, and Betz, 2008, for German; and Houtkoop-Steenstra, 1991, for Dutch, to cite a few) and it is the topic of several dedicated university courses across Europe and North America.

While the CA community has been growing internationally, the examination of Greek talk-in-interaction through this perspective is still in its infancy. Given the cumulative character of work within the field and the growing interest in conversation analytic accounts of Greek data, there is considerable potential for a Greek CA community to take root and prosper by putting forth a series of important questions on the linguistic and socio-cultural particularities of Greek talk-in-interaction. These possibilities are reflected in the areas addressed in this special issue: sequence organisation, turn construction,

\footnotetext{
${ }^{1}$ At the same time as Sacks was developing an interest in interaction, scholars in mainstream linguistics were primarily interested in the workings of language as an abstract system; similarly, pragmatically oriented work in the philosophy of language was focussing on single utterances which were neither situated in the context of the interaction (e.g. isolated 'speech acts' in Austin and Searle) nor naturally occurring (e.g. constructed examples in Grice; cf. Antaki, 2002).
} 
prosody, storytelling and code-alternation. A close look at the sequence organisation of Greek conversational data reveals how different actions, such as opposition, accepting and rejecting advice, and producing humorous turns, are managed. In addition, the present collection sheds light onto previously unidentified, minute occurrences in Greek conversation of phenomena such as laughter, responses to summons, continuers, openings and closings of storytelling sequences, etc. All of these carry a significant cultural load and offer themselves to cross-cultural inquiry. We therefore believe that the time is ripe for an edited journal issue dedicated to conversation analytic studies of different varieties of Greek, which will provide a point of reference for scholars and students interested in Greek talk-in-interaction, be they practitioners of CA in other languages or primarily interested in Greek. The specific aims of this special issue are thus: a) to showcase ongoing research in Greek CA; b) to help identify new and as yet unexplored areas in Greek CA; c) to offer social scientists and students of language a point of reference for empirical studies of Greek talk-in-interaction; d) to raise awareness of current trends and debates within the field among scholars and researchers of Greek; and e) to facilitate contrastive analysis of Greek and other languages from a conversation analytic perspective.

\section{Conversation Analysis: An overview}

\subsection{Background and foundations}

The intellectual roots of CA may be traced back to sociology, and more specifically to the work of Harold Garfinkel in ethnomethodology (1967, 2003; Psathas, 2003) and that of Erving Goffman on the 'interaction order' (1983), both of whom were interested in language use as a component of social action (Heritage, 1995). Starting from a critique of the Parsonian model of social action, Garfinkel (1967) claimed that members ${ }^{2}$ are active agents and not just cultural dopes that seamlessly align themselves with social norms and rules. In his work, Garfinkel emphasised the accountability of action rather than rule following. More specifically, he was interested in the ways in which social members ('ethno-') structure their reality and make sense of it through practical methods ('-methodology'). CA is considered an empirical application of

\footnotetext{
2 The ethnomethodological concept of 'member' does not refer to a person or a social category but to the 'mastery of natural language' through which people appear to 'objectively' display 'commonsense knowledge of everyday activities' (Garfinkel and Sacks, 1970: 342; cf. Coulon, 1995: 26-27).
} 
ethnomethodology in that it tries to capture the methods through which participants organise and understand conversation. ${ }^{3} \mathrm{~A}$ key ethnomethodological point taken up and further developed in CA is the importance of analytic categories only insofar as these are relevant for participants themselves (Hutchby and Wooffitt, 2008). ${ }^{4}$

Following Goffman's insight that the interaction order can be an object of investigation in its own right, in CA the internal organisation of conversation is studied through naturalistic means (Schegloff, 1988; Heritage, 1995). Participants orient towards organised conversational structures and normative requirements, sometimes without realising it. When speakers depart from such normative requirements, their actions are subject to interpretation by interlocutors and they become accountable, more often than not, in the course of the conversation. Thus, the emphasis is placed on the public, accountable character of action rather than on rigid principles of rule following.

A central insight of CA is the role of action as both 'context-shaped' and 'context-renewing' (Heritage, 1984: 280-283; Schegloff, 1987b). An action is shaped by the immediate context of talk-in-interaction in which it appears, but it also renews context in that it becomes a platform upon which subsequent action unravels itself (Heritage, 1984: 280). The goal of the analysis is, then, to bring to the surface 'procedural consequentiality', that is, the way in which conversational context is shaped by, but also has consequences for, upcoming talk (Schegloff, 1991: 52-53). The institutional context may also have consequences for the shaping of conversational structures: for instance, turn-taking (the alternation of speakers at talking) in the courtroom is characterised by a rigid structure with clear pre-allocation of turns (Atkinson and Drew, 1979; Schegloff, 1991: 54).

However, any a priori connection between the social context and the conversational structure would be premature. For instance, the fact that the participants are situated in a courtroom setting does not mean that the 'courtroomness' of the setting projects itself upon every possible aspect of the interaction, or that the roles of judge, jury, defendant etc. are omni-relevant at every possible juncture during the exchange. Other aspects, such as participants' display of expert knowledge or the invocation of practical epistemology, may become

\footnotetext{
${ }^{3}$ Despite their common roots, differences between ethnomethodology and CA also exist, especially as to the importance of the wider context and of members' knowledge in understanding and analysing interaction (McHoul, Rapley and Antaki, 2008).

${ }_{4}^{4}$ The ethnomethodological roots of CA are, however, sometimes forgotten or misunderstood in some applications of CA, especially by linguists (see also below; for the importance of the sociological reasoning behind CA, see Seedhouse, 2004: 46-52).
} 
relevant at some point during the courtroom session. We therefore need to, at least initially, refrain from linking micro- and macro-level, treating interaction as a context-in-the-making instead (Schegloff, 1987b: 220-228). This, however, does not preclude that the ways in which social categories, attributions and roles may be linked to, and emerge from, talk-in-interaction could be tackled at a second level of analysis (Schegloff, 1991: 51-52).

\section{$2.2 C A$ and other fields/disciplines}

As one might expect from CA's emphasis on social categories as emergent in talk-in-interaction, a clear distinction is to be made between CA and Discourse Analysis (DA). By way of a general definition (though not inclusive of all possible 'schools'), Discourse Analysis may be defined as the study of the rhetorical mechanisms and repertoires on both a local and an abstract level (often open to different possible interpretations by analysts), where either spoken or written discourse can be analysed as text. In contrast, conversation analysts study talk in its local context of production and the rationale of analysis is quite rigid and well defined. ${ }^{5}$ DA consists of a wide array of approaches drawing from (socio)linguistics, psychoanalysis, etc. that includes, but is not limited to, the Birmingham School (Sinclair and Coulthard, 1975), Critical Discourse Analysis (CDA; Fairclough, 1995), Sociological Discourse Analysis (in the area of the Sociology of Scientific Knowledge; Gilbert and Mulkay, 1984), and Discursive Psychology (Edwards and Potter, 1992) - although the boundaries between these different 'schools' are not always clear-cut. Among these approaches, only Discursive Psychology draws directly, though not exclusively, from CA.

A stark controversy erupted almost fifteen years ago between CA and CDA (Wetherell, 1998; Schegloff, 1998a; van Dijk, 1999; Billig, 1999a, 1999b; Schegloff 1999a;, 1999b). Briefly, CDA focuses on issues of power and domination in discourse and in the wider society. CA criticises CDA for assuming in advance the relevance of extra-conversational factors which are then mapped onto the analysis. CA's fundamental difference with CDA can also be extended to the tensions between CA and mainstream sociology. The reluctance of CA to take into consideration sociological terms and issues has led to the criticism that CA fails to address the 'sociological agenda' (Hutchby, 1999, Hutchby and Wooffitt, 2008). Conversation analysts' response to this criticism is that traditional questions in mainstream sociology are actually inverted in CA:

\footnotetext{
${ }^{5}$ For further comparison and discussion of CA and DA, see Wooffitt (2005).
} 
instead of searching for ways in which power structures, for instance, are mapped onto talk, the conversation analyst investigates whether and how participants in interaction are oriented towards issues of social power (Hutchby and Wooffitt, 2008: 208-9). Schegloff (1987b) argues for the independence of the sphere of talk-in-interaction and cautions against the early connection of micro-scale phenomena of interaction to the macro-level (e.g., social attributes of participants such as social class, gender, ethnicity, etc.) which may lead to reductionism and arbitrary conclusions. Important insights into the local character of social interaction but also large-scale structural issues risk being lost in such early attempts. While this means that conversation analysts are reluctant to assume an early micro-macro linkage, it does not exclude that they can actually make micro-macro connections based on the orientations of the participants themselves (Hutchby and Wooffitt, 2008). Indeed, CA is interested in macro-structures — and power in particular — as far as institutional interaction is concerned (Hutchby and Wooffitt, 2008: 209).

Despite its sociological origins, CA has enjoyed close relations with linguistics and has indeed found a dedicated audience and practitioners among linguists. Especially as far as the study of grammar and prosody in naturally occurring talk is concerned, CA has a lot to contribute to the discipline (see sections 3.1 and 3.2 below). It should be noted, however, that a marked difference exists between a conversation analytic and a (mainstream) linguistic approach towards data, the former primarily focusing on the action trajectories of interaction (i.e. what participants appear to be doing through talk) rather than in the (inventory of) abstract, structural features of language. CA is also distinct from many sociolinguistic approaches in that it draws its data exclusively from naturally-occurring exchanges and bases its analysis on the displays, accounts and understandings of the participants (adopting an emic, that is, the participants', perspective) rather than of the analyst (reflecting an etic perspective) (Seedhouse, 2004; Hutchby and Wooffitt, 2008: 228-230; Terkourafi, 2009). This difference is not always adequately taken into account by linguists who employ CA, thereby resulting in structural and/or normative descriptions of conversational data.

One common misconception about CA among linguists concerns the study of turn-taking or repair as formal rules and sets of units in the linguistic sense (Seedhouse, 2004: 46-52). This misconception can result in the transcription and coding of patterns without paying due attention to the CA notion of talk as social action. While this may be attributed to the fact that the ethnomethodological underpinnings of CA were never adequately explained to the linguists - not even by Sacks, Schegloff and Jefferson in their seminal paper on turn-taking (Sacks et al., 1974) — recently there have been some 
serious attempts at a rapprochement between CA and linguistics, with the former taking more seriously into consideration the technical aspects of the grammar and the prosody, and the latter focussing on naturally occurring data and the action orientation of participants (see sections 3.1 and 3.2 below).

As already mentioned, CA is employed as an approach for the study of talk-in-interaction in its own right (this is the 'pure' version of CA, close to Goffman's idea of the 'interaction order'). But it can also be employed as a complementary method. For instance, CA can be an important tool for the study of interviews and life stories in the social sciences, an asset which has not yet been adequately explored or developed (Baker, 1997; Silverman, 1999; Drew et al., 2006). A step in this direction has been taken by Discursive Psychology, which, as mentioned above, is a type of discourse analysis with a strong CA take, used for the study of cognitive states as they are manifested in discourse. Without denying the importance of underlying psychological processes, Discursive Psychology embraces the position that what are traditionally seen as cognitive and psychological processes can be studied as discursive practices (Hutchby and Wooffitt, 2008: 220). This approach was developed by Derek Edwards and Jonathan Potter (1992) at Loughborough University and is continuing to attract significant attention and publications under the rubric of 'discourse and cognition'. 6

\subsection{Collecting and transcribing data for $C A$}

The empirical basis of conversation analysis is the use of recordings of naturally occurring data. In order to uncover details of the organisation of talk-ininteraction and to produce a successful analysis, recorded data (in the form of analogue tapes, or more recently, digital audio or video recordings) are essential. Conversation unfolds very quickly in real time and it is impossible for an observer to capture the exact timing and details of naturally occurring talk based solely on memory and field notes. Recordings enable the analyst to study the data in detail with repeated listening over time. Mere observation or a priori assumptions weaken the analysis and any contextual and linguistic details resulting from it. Heritage stresses that "CA has approached the world of social interaction in the same spirit as the naturalist" (1995: 396). This is a data collection method that captures as accurately as possible human action: the way in which conversationalists manage their turns and actively display

${ }^{6}$ See, e.g., Te Molder and Potter, 2005, as well as the special issue of Discourse Studies 8:1 (2006) on "Discourse, Interaction and Cognition", and van Dijk's editorial therein. 
meanings and identities (ibid.). Thus, experimental or elicited data are not adequate for the analysis of talk-in-interaction. Although the problem of the observer's paradox (Labov, 1970: 32) is well known and acknowledged by conversation analysts, their aim remains to make their recordings as nonintrusive as possible.

In the early days of CA, audio recordings were predominantly used for the collection of naturally occurring conversations such as telephone interactions or face-to-face interactions (ten Have, 1999). Even though the data were valuable for analysis, they were felt to provide only partial information of the particular conversational event. The recorded events might have contained important non-verbal information that the audio recording could not 'capture'. Whereas audio recordings are still employed, video recordings are becoming more widespread in an attempt to capture and describe non-verbal interaction as well.

Repeated listening to the recordings results in the transcription of the recorded talk-in-interaction. The transcriptions of the recorded interactions "are not thought [of] as 'data"' (Hutchby and Wooffitt, 2008: 69) and they do not aim to replace the actual data, i.e. the recordings of naturally occurring talk. The data of CA are the actual recordings and the transcriptions of these recordings simply facilitate analysis. As Hutchby and Wooffitt put it, the transcripts are "a convenient referential tool", a "representation' of the data' and the recording is "a 'reproduction' of a determinate social event" (ibid: 70).

The transcription is supposed to be done by the analyst as the analyst might get some 'hunches' at this stage and focus on some phenomena that may be analysed later on. Transcription in CA entails writing down in a detailed manner features of a conversation such as the exact onset and termination of overlaps, the length and position of pauses, any non-verbal sounds like breathiness and laughter, and the marking of stresses or louder segments. Jefferson $(1989,2004)$ developed a system of standardised conventions in order to facilitate transcription of recorded data. The transcriptions in this issue follow her guidelines.

For researchers in CA, orthographic transcription of the data is not a priority and is frequently sacrificed for the benefit of providing a visual representation that is as close as possible to the acoustic signal itself. Additionally, in the case of non-Anglo/American data addressed to an international audience, as is the case with the articles in this issue, transcribed extracts are frequently presented in Roman transliteration (though not in the IPA). This is mainly for two reasons: first, in order to make the text accessible to those that may not be familiar with the original language of the recordings, and second, in order to facilitate access to the text by non-linguists (CA was, after all, started by sociologists rather than linguists). In the current issue, we have also followed this 
convention. In the transcribed extracts, the original Greek utterance in Roman transliteration is followed by an approximate translation. Additionally, information may be provided in a grammatical gloss (where relevant).

\subsection{Method and units of analysis}

The basic methodology of CA is 'analytic induction', that is, the systematic search for commonalities among the cases under study in order to construct and reconstruct general ideas and generate concepts (Ragin, 1994, cited in ten Have, 1999: 38-39). Part of analytic induction is the comparative method as well as 'deviant case analysis' (see below). In order to adequately describe and analyse a phenomenon, it is essential that the data be exhaustively processed (Silverman, 2006: 296-299).

The object of inquiry for CA is social interaction as an accomplishment: interaction occurs within a normative and moral context, which becomes publicly available through sequences of turns and actions. Social action is situated in the 'here and now' and conversation itself offers the tools for understanding action as publicly available and accountable. Even in cases where features of interaction have been misinterpreted by participants, actions can be located and analysed (Schegloff, 1996: 172-173).

As far as the actual CA analysis is concerned, it is difficult to discern clearcut steps: there are neither hard-and-fast rules, nor are there steps followed in a linear, one-way direction. Below, we provide a roadmap to key stages in the analysis, taking into consideration that the craft of studying conversational data is, in reality, a much more complicated process:

(1) CA analysis begins with an 'unmotivated listening' and close study of conversational data (Sacks, 1984: 27). That is, the analyst avoids any preconceptions or clear hypotheses as to where the research could possibly lead. As already mentioned, conversation analysts are reluctant to assume properties of social structure or abstract features of interaction in advance. This does not mean that analysis begins in a vacuum: at this point, some early observations and 'puzzles' may appear (Schegloff, 1996: 174-176).

(2) At a second stage, the analyst makes an inductive search for material that could possibly be related. A 'core collection' of conversational excerpts with recurring characteristics is put together. ${ }^{7}$ These cases are not clustered together in pre-defined theoretical categories; rather, they are grouped based

${ }^{7}$ It is also relatively common in CA to work with case studies, where a single conversational episode is analysed in great detail (Schegloff, 1987a). 
on the characteristics which they demonstrably share (Hutchby and Wooffitt, 2008; Schegloff, 1996: 176-180).

(3) Next, the analyst tries to reach a 'candidate solution' concerning the nature of the phenomenon under study (Schegloff, 1996: 181-189). ${ }^{8}$ The aim of the analysis is to understand the ways in which participants are managing context and the ways in which action is shaped rather than the morphosyntactic structures of language (Heritage, 1995). In order to find a connection with the prior turns and actions, conversation analysts employ 'sequential analysis': the meticulous study from the point of interest backwards towards the beginning of the sequence. ${ }^{9}$ At this point the interactional context is analysed. Sequential analysis is based on a 'next-turn proof procedure' because participants display their understanding of a turn in their next one (Hutchby and Wooffitt, 2008: 13). The phenomenon is then meticulously described as far as the units it is composed of, its position in the sequence, its design, and the actions it is doing are concerned. Analysis leads to the emergence of regularities and patterns that constitute the phenomenon (Seedhouse, 2004) allowing the normative orientations of participants, the features of their sociality, and the methodic character of their practices to be revealed. Additionally, findings of prior CA research can add to the understanding of the sequential environment and of the phenomenon under study (Schegloff, 1987a).

(4) Lastly, analysts move on to less transparent cases which were initially difficult to analyse and to instances of avoidance or non-occurrence of the phenomenon in the data (Schegloff, 1996: 189-199). The cases that differ from the observed pattern, where participants deviate from the type of action in the core collection, underline the normative properties of the phenomenon. This is called 'deviant case analysis' and its aim is to explore the type of the deviation, the reason for its occurrence, and the way it is being managed (Hutchby and Wooffitt, 2008). There are also 'marginal' cases: those that can neither be included in the recurring pattern of the phenomenon, nor are deviations from the normative requirements. Marginal cases define the "nature, scope and limits of conversational practices" (Heritage, 1995: 399). An example of a marginal case is the absence of a phenomenon at points where we would normally expect it to occur according to the core collection.

A basic unit of analysis in CA is a conversational 'turn', i.e. the speaker's utterance every time s/he takes a turn to speak. A turn may vary in size from

${ }^{8}$ This means that what constitutes the phenomenon is not yet available.

9 Sequential analysis differs from sequence organisation. Sequence organisation is the way in which a conversation is organised and unfolds (Drew and Heritage, 1992b: 37-42). Points of interest of sequence organisation are question-answer sequences, preference organisation, the organisation of repair, topic change/shift, etc. Through this dimension of analysis we can see how opportunities for action are either enabled or disabled (Heritage, 1997: 169). 
one to more smaller units (turn constructional units/TCUs): a turn may consist of anywhere from one word up to many sentences (Sacks, Schegloff and Jefferson, 1974: 702-703; Nofsinger, 1991). TCUs are the building blocks of turns, organised in terms of grammar (i.e., they are sentences or clauses), phonetics (especially intonation), and action (what is done at particular interactional junctures) (Schegloff, 2007a: 3-4). The exact timing of a turn is important: a straightforward answer, for instance, is qualitatively different from a delayed one that possibly projects a rejection. Also, a turn is doing certain action(s) according to its position in sequence: an action is a consequence of a prior one and simultaneously invites a next one.

A conversation comprises sequences of turns and actions, with the 'adjacency pair' as the basic sequential unit (Nofsinger, 1991; Schegloff, 2007a). These are methodically positioned pairs of utterances where the first pair part is (expected to be) followed by the second one. Examples of such pairs are greeting-greeting, question-answer, offer-acceptance/rejection, and assessmentagreement/disagreement. The type and manner in which second pair parts are uttered is important. For instance, the acceptance of an invitation is a preferred action, while its rejection is dispreferred (Hutchby and Wooffitt, 2008). The CA notion of preference (Pomerantz, 1984) is neither a psychological one nor a positive evaluation of behaviour. Rather, a preferred action is more frequent and is directly produced. The sequential property according to which particular second pair parts follow specific first ones is called 'conditional relevance' (Schegloff, 1968: 1083). This property helps explain the occurrence or absence of a conversational unit. A conversational opening, for instance, can be done with a greeting as a first pair part; its appearance makes a second pair part (the return of the greeting) conditionally relevant. In the absence of this second pair part, participants make contextual inferences based on their understanding of conditional relevance at that point in the conversation.

Another way in which turns are connected to each other is through turntaking, that is, the way in which speakers take turns to speak. There is an implicit rule set in everyday conversation to which participants orient. In this system, one speaker tends to talk at a time and turns occur with minimum gap and minimum overlap between them (Sacks, Schegloff and Jefferson, 1974: 704-706). ${ }^{10}$ The turn-taking system of ordinary talk appears slightly modified in institutional settings such as the courtroom (Atkinson and Drew, 1979), the classroom (McHoul, 1978), and the news interview (Greatbatch, 1988

10 There is a 'rule set' which occurs at least once in conversation:

(1) In the first possible transition relevance place (TRP), (where a turn appears to be reaching its end grammatically, intonationally and pragmatically): 
reported in Heritage, 1995: 408). The study of turn-taking requires pinpointing speaker transitions, overlaps, pauses or latching between turns.

When troubles in conversation occur (troubles of hearing, speaking or understanding), a mechanism of repair is put forward (Schegloff, Jefferson and Sacks, 1977). Sometimes current speakers themselves rectify the problem in their own talk (self-initiated self-repair). At other points, an interlocutor may signal that something is to be repaired, which is then repaired by the current speaker (other-initiated self-repair). In yet other cases, the current speaker may signal a problem in his/her own talk (e.g., through a word search) and may provide turn space to the interlocutor to rectify (self-initiated otherrepair). Lastly, a fellow speaker may target repair and move on to execute it (other-initiated other-repair). Among these practices, self-initiated self-repair is a preferred action in conversation (Schegloff, Jefferson and Sacks, 1977).

\section{CA: main areas of analysis}

\subsection{Grammar-and-interaction}

As mentioned above, an area of cross-fertilisation and dialogue between CA and linguistics is that of 'grammar-and-interaction' within the field of 'interactional linguistics' (Couper-Kuhlen and Selting, 2001). In their introduction to Interaction and Grammar, Schegloff, Ochs and Thompson (1996) put forward three possibilities as to how grammar and interaction organise one another, which are then further explored in the contributions to that volume. These three possibilities are: (a) grammar organises social interaction; (b) social interaction organises grammar; and (c) grammar is a mode of interaction.

The first possibility maintains a traditional notion of grammar in that it sees grammars as "abstract mental structures that organise linguistic elements within utterances that in turn comprise social interaction" (Schegloff et al., 1996: 34). In this case, grammar provides the resources for carrying out social interaction. Work on how grammar organises turn constructional units or repairs falls under this possibility. The second possibility considers grammar to be the outcome of interaction and bearing a close relationship to it (Schegloff et al., 1996). On

(a) current speaker selects next. If this does not occur, then

(b) another speaker may self-select. If this does not occur either, then

(c) current speaker may continue

(2) If in the first possible TRP (1c) occurs, then rules (a)-(c) reapply in the next possible

TRP until speaker transition occurs (Sacks, Schegloff and Jefferson, 1974: 704). 
this view, grammar is designed for interaction and it is also vulnerable to interaction, that is, 'syntax-for-interaction'. This possibility was explored by Fox, Hayashi and Jasperson (1996) who demonstrated, among other things, how repair in English and Japanese expanded syntactic practices, clustering together "ungrammatical" syntactical units. Finally, the third possibility sees grammar as a mode of social interaction. According to this line of argument, grammar is a resource for interaction, an outcome of interaction and part of the essence of interaction. Grammar is seen as lived behaviour. According to Sorjonen (1996), the Finnish particles 'niin' and 'joo' are typical interactional elements.

Whichever view is adopted, CA proposes that grammar and interaction are interconnected and that their inter-relationship needs to be studied. Social interaction does not operate at the level of deep linguistic structures, but on the basis of recognizable turns and actions and on the surface level of grammar and prosody as shaped by, and shaping, naturally occurring talk (Sidnell, 2009b).

\subsection{Prosody}

Another set of conversation analytic studies focuses on the interface of conversation and phonetics. In an early study, Gumperz (1982) underlined the importance of examining how prosody interacts with other modalities to signal thematic connections and to induce an interpretation of communicative intent. He explored how participants in a conversation use prosody to initiate and carry out conversations. Specifically, he examined intonation, changes in loudness, stress, variations in vowel length, phrasing, and overall shifts in speech register.

Schegloff (1998b) focused on the study of prosody in talk-in-interaction and how prosody offers a set of resources and practices to participants to interact. Based on the analysis of three conversational episodes, he examined, first, how pitch peaks can be used and understood as projecting that "a next syntactic possible completion is the designed end of the turn" (Schegloff, 1998b: 235); second, the initial turns in the opening of a telephone conversation; and, finally, the important role that prosody can play in the constitution of action which an utterance is implementing. Among other things, he concluded that a pitch peak can project the upcoming of a possible turn completion at the next possible grammatical completion of a unit that is being produced. He also pointed out that other prosodic features occurring in talk-in-interaction can be best understood with reference to instances of turn design and turn organisation. More recently, the organisation of phonetic detail in relation to social actions based on data from talk-in-interaction has been the theme of a collection edited by Couper-Kuhlen and Ford (2004). 


\subsection{Narrative analysis}

Narrative analysis started receiving attention with Labov's (1972) model of narrative structure based on data collected from interview narratives. The narratives occurring in sociolinguistic interviews can be viewed as a response to the researchers' elicitation questions (Georgakopoulou, 2006). Conversely, within the CA framework, the focus is on narratives in talk-in-interaction which are not prompted by the researchers' elicitation techniques. As Schegloff (1997: 99) points out, narrative analysis in CA must take into account "the different setting of 'orality'... in which different speech-exchange systems with different turn-taking practices differentially shape stories and the practices of storytelling". He further stresses that the context of sociolinguistic interviews and the elicitation techniques for narratives have an effect on the "motive force of the telling" (Schegloff, 1997: 99). Keeping in mind that "people tell stories to do something - to complain, to boast, to inform, to alert, to tease, to explain or excuse or justify" (Schegloff, 1997: 97), conversation analysts are interested in how narratives in talk-in-interaction are initiated and told. Hutchby and Wooffitt (2008: 123) stress that "stories are not produced in a vacuum, but their telling is always situated within interactional and sequential contexts". Therefore, CA is interested in the sequential organisation of storytelling in talk-in-interaction.

\subsection{Institutional interaction}

Institutional interaction, that is, interaction which is taking place in institutional settings such as courtrooms, classrooms, news interviews, medical examination rooms etc., has attracted a lot of attention, especially in the last two decades (Drew and Heritage, 1992a; Sarangi and Roberts, 1999; Arminen, 2005). Research has mostly focused on the comparison between everyday and institutional interaction. The organisation of institutional talk is a modification of everyday conversation and the range of interactional practices is considerably limited compared with ordinary talk (Drew and Heritage, 1992b). For instance, the expression of sympathy or agreement is absent or very limited during news interviews. Another point of agreement among conversation analysts is that ordinary talk is rather symmetrical, as far as the distribution of conversational rights and obligations is concerned; it is based on local contingencies and is "independent of the extradiscursive identities of participants" (Drew and Heritage, 1992b: 48). On the contrary, institutional interaction is structured on the basis of a social hierarchy displayed in participants' actions 
(ibid.). ${ }^{11}$ Institutional talk is an interaction between expert/non-expert which requires a careful analysis of knowledge in action. Therefore, apart from lexical choices, sequence organisation, turn-taking, and overall structural organisation, issues of social/practical epistemology and social relations are also discussed (Drew and Heritage, 1992b; Heritage, 1997).

\subsection{Feminist $C A$}

Although the conversation analytic study of gender initially encountered problems with respect to the a priori assumption and reduction of the gendered identities of participants in the data, the branch of Feminist CA has tried to take into consideration the relevance of gender both for feminist issues and for participants themselves and has been evolving over the past decade (Kitzinger, 2000, Speer, 2005; Benwell and Stokoe, 2006). In line with CA principles, an analyst cannot attribute gender categories in interaction unless this is done by the participants themselves. However, it has been argued that this does not lead to interesting novel findings for the discussion of gender issues (Stokoe and Smithson, 2001). A constructive discussion between CA and sociolinguistics, on the other hand, could lead to analyses which stay faithful to the data but at the same time promote feminist discussion and emancipatory work (ibid.).

\subsection{Membership Categorisation Analysis}

Membership categorisation analysis (henceforth MCA) was an approach developed by Harvey Sacks $(1972,1979,1992)$ in parallel with CA. Although it is also rooted in the ethnomethodological tradition, it did not develop as systematically as CA. MCA aims to understand the ways in which members categorise themselves and others by studying how they select words to refer to self and others, and how these are hearable by interlocutors (Schegloff, 2007b). In other words, MCA is about categories in use (such as woman, man, Greek, plumber, conservative, bisexual etc.). Particular choices are consequential and lead to specific trajectories in talk. Sacks was especially interested in the way categories could be heard as going together through mechanisms such as 'membership categorization devices' (MCDs) (Sacks, 1972). A well-known

${ }^{11}$ However, any interaction can be a-symmetrical in its moment-by-moment unfolding (Linell and Luckmann, 1991 cited in Drew and Heritage, 1992b). 
example of such a device is found in the utterance "The baby cried. The mommy picked it up", where, according to Sacks (1972), we can 'hear' that it is the baby's mother that picked it up due to the MCD 'family'. Categories also carry with them particular rights and obligations, in the form of the category-bound activities which can be evoked in talk as normative assumptions (for instance, in the example above, the category 'mother' is bound with activities/expectations of being caring and looking after her child; see Antaki and Widdicombe, 1998; Antaki, 2002).

\subsection{Multimodal interaction}

An expanding area within CA is the study of multimodality, and in particular the analysis of visual communication. Researchers of talk-in-interaction are increasingly realising that social actors are embodied creatures who interact with both the physical and the material world around them. Although it is difficult to systematically describe non-verbal interaction (e.g. posture, gesture, gaze), there has been an increasing number of publications in this area over the past decade (Goodwin, 2000; Whalen et al., 2004; Mondada, 2007), including the study of multimodality in workplace studies (Whalen et al., 2004). One of the most systematised phenomena in multimodal interaction is gaze (Goodwin, 2000). A particular area of interest in this regard is the way gaze operates to signal turn completion and speaker transition (Rossano, 2005).

\subsection{Further areas of conversation analytic interest}

In addition to the areas of overlapping interests and cross-fertilisation outlined above, CA has also contributed to the study of interaction through the use of technology, of atypical talk-in-interaction, and of code switching. Suchman's (1987) pioneering study of human-machine interaction criticised existing user models of cognitive and computer science for attributing attachment to a pre-existing plan and, adopting an ethnomethodological and CA orientation, showed how situated action is primarily ad hoc. Studies of conversation and technology further flourished in the 2000s with the analysis of talk by operators in an urban transport system (Luff and Heath, 2002), cockpit interaction (Nevile, 2004), and mobile phone conversations (Hutchby, 2001; Hutchby and Barnett, 2005). Research on communication in workplace settings with the use of new technologies has more specifically come to be known as 'workplace studies' (Luff, Hindmarsh and Heath, 2000).

CA studies of atypical talk-in-interaction focus on the communication of people with speech disorders in real life situations rather than on their 
performance in clinical settings. In this respect, CA studies highlight the competencies of people with speech disorders, as opposed to research which treats these speakers as inherently deficient (Hutchby and Wooffitt, 2008). Related CA research has focused on aphasia (Wilkinson, 1995; Goodwin, 2003b), autism and Asperger's syndrome (Wootton, 2002/3; see also Goodwin, 2003a). Some practical implications of CA are also being put forward in what is called 'interaction therapy,' where video recordings of interactions between sufferers and their families are played back to participants, in order to enhance understanding of the problems of aphasic speech in family interaction (Wilkinson, 1999).

CA approaches code-switching and language transfer (language alternation) as a conversational activity (Auer, 1988, 1998). Unlike macro-sociolinguistic and grammatical approaches to the same phenomena, this approach stresses the local functioning of alternation and the way in which the alternation contributes to the sense-making of participants, taking grammatical restrictions into consideration at the same time. ${ }^{12}$

\subsection{Cross-cultural comparisons}

Last but not least, the comparative study of talk-in-interaction across cultures is finally beginning to take shape. After over forty years of conversation analytic scholarship which has gradually expanded from the analysis of AngloAmerican data to different languages, the first comparative attempts have recently appeared (Sidnell, 2009b; Schegloff, 2009). These studies focus on comparisons between phenomena that have been extensively documented in different cultures from a CA point of view, such as turn-taking, repair, repetition, and gaze (Sidnell, 2009a).

Although there is vast cross-cultural diversity as far as the languages spoken and the applicable sociolinguistic norms (e.g., regarding posture), there are also considerable commonalities in interactional features across cultures (Sidnell, 2009b). People across the globe attend to actions, attempt to make sense of, and interpret, the intentions of their interlocutors, and encounter troubles at talk which they try to rectify in different ways. All these are generic organisational features and mechanisms of sense making which may manifest themselves differently in different cultural settings (ibid.). A precondition for fruitful cross-cultural comparison is, of course, first to develop a systematic

${ }^{12}$ For details on empirical CA work on code-switching and cross-fertilisation between the two see the special issue of the Journal of Pragmatics 37: 3 (March 2005) edited by Li Wei. 
study of conversational phenomena in different languages. The studies collected in this issue represent a first step in this direction, as far as Greek talkin-interaction is concerned.

\section{Conversation analytic studies of Greek talk-in-interaction}

Even though the development of a Greek CA community is at its early stages, some studies have nevertheless employed CA as the primary (though not always singular) approach to understanding their data. In this section, we summarise a selection of the most relevant of these studies in chronological order of appearance.

Among the first to apply CA methods to Greek data, Makri-Tsilipakou combined CA with politeness theory (Brown and Levinson, 1987) to explore the ways in which interruptions (1994) and agreement and disagreement (2002) are accomplished in conversation with reference to gender. She found that women appear to be engaged more in face-saving strategies and affiliative work to maintain interaction, whereas men appear to benefit from an asymmetrical distribution of conversational rights. Makri-Tsilipakou has also employed CA and MCA to study the use of diminutives (2003), concluding that it is a phenomenon of 'doing culture', rather than a gendered practice.

Bozatzis's (1999) analysis of modern Greek national identity in talk-ininteraction highlighted "the flexible discursive uses of cultural stereotypes of modern Greek national identity” (Bozatzis, 1999: 1). Using audio recorded talk-in-interaction with Greek students in the UK and Greek employees in the European Commission, and asking the participants to report their living experiences and their countries of residence, he observed that there is a deployment of cultural stereotypes of modern Greek national identity and that these stereotypes are employed to turn away any negative identity inferences about the speakers. His analyses showed that there is repetition of a cultural ambivalence of modern Greek national identity in talk, and also explain the grounds for a convergence of ethnographic arguments concerning the symbolic uses of stereotypes with social psychological arguments regarding their interactional uses (ibid.). More recently, Poulios has also employed CA and MCA to explore identity. He analyses the construction of elderly identities in troubles-telling in ordinary conversation (Poulios, 2004), in a television reality show (Poulios, 2009), and in television interviews with popular Greek actresses and actors (Poulios, in press). In line with a conversation analytic rationale, he has argued that identities are not fixed categories, but are constructed as social processes that involve and invoke cultural knowledge. 
Tzanne (2000) employs CA methods to study instances of miscommunication; she presents different ways through which participants dynamically re-establish understanding and instances of repair avoidance. Hadjidemetriou (2001) explored the syntactic organisation of self-initiated self-repairs in Greek conversation. Instances of self-initiated self-repairs were analysed in order to determine their syntactic and conversational organisational patterns as they occurred in natural interactional settings.

Telephone calls, an area that has been extensively discussed in CA work in other languages, have been analysed for Greek by Pavlidou (2002) and Sifianou (2002). Pavlidou (2002) explores the characteristics of the initial section of telephone calls in Greek and in German by examining the use of phatic utterances after greeting, partner identification, and the reason for making the call. Her analysis showed that Greek speakers employ phatic utterances to improve their relationship by showing involvement and by encouraging more intimacy. German speakers, on the other hand, focused more on the content of the call. With respect to the closing section of telephone calls, Pavlidou found that when the telephone calls were between individuals who were familiar with each other or had an intimate relationship, there was a divergence from a dyadic turn-taking structure in Greek closings, whereas in German ones, the closing was richer in content including, e.g., references to future contact. Based on these findings, Pavlidou (ibid.) has argued that the analysis of Greek telephone closings among familiars displays cultural features of Greek conversation with an orientation towards solidarity and involvement. Sifianou (2002) explores telephone call openings in Greek. In contrast with the findings of other CA studies of telephone calls, she argues that in the Greek case, telephone calls among intimates may not contain greeting-greeting sequences but only the summons-answer and how-are-you sequences.

Georgakopoulou (2006, this volume) focuses on the analysis of narrativesin-interaction collected from adolescents' conversations and private email messages, and examines how narrative analysis can be revised (tellership, tellability, embeddedness) based on the different sets of data that she uses. An analysis of narrative also appears in Petraki et al. (2007), an ethnomethodological study of storytelling by three generations of Greek-Australian women. Finally, Archakis and Skarvelaki (2009) apply CA to the analysis of story openings in oral narratives in interaction between young friends. The authors conclude that story openings project participants' narrative discourse identities and open 'narrative communicative channels'.

Vasilopoulou (2005, 2006) employs CA to examine Greek classroom interaction, the way in which pupils are gradually socialised into and through the use of institutional talk (turn-taking, Initiation-Reply-Evaluation sequences, 
teachers' repetitions), and employ grammatical resources and ethnomethods to convey meaning. In other work, she has also applied feminist CA and MCA to the analysis of heterosexist talk in Greek ordinary conversations (Vasilopoulou, 2010).

Finally, Kaimaki (2009, this volume) uses a CA approach to explore the organisation and function of pitch and other phonetic features in English and in Greek conversation. More specifically, her thesis focuses on the following two themes: "variations in, and associations between, phonetic design, function, and interactional sequential organisation, [and] the extent to which [the] pitch design of one turn is consequential for how the interaction develops - specifically for what happens in the next turn in interactional sequence" (Kaimaki, 2009: 208). She also examines "the implications of taking sequential organisation and participant orientation into account when establishing comparability and when understanding what it means to talk of the linguistic function of pitch contours" (Kaimaki, 2009: 208). Her data come from a corpus of telephone calls between Greek speakers. Her results showed that there is a possibility of free variation in speech contours in some places in interactional structure.

\section{This issue}

The studies in this special issue cover a wide spectrum of topics in Greek talkin-interaction, some already previously investigated and some novel. In the opening article, 'The prosodic framing of humour in conversational narratives: evidence from Greek data,' Argiris Archakis, Maria Giakoumelou, Dimitris Papazachariou and Villy Tsakona explore the role of prosody in framing humour within conversational storytelling. The authors' focus is 'jab lines', defined (following Attardo, 2001) as words, phrases, or sentences that form turn constructional units and are "fully integrated in the text, and indispensable to the development of its plot, without, however, causing its reinterpretation" (Archakis et al., this volume). Their study encompasses a qualitative as well as a quantitative aspect, which is rather uncommon in CA practice.

Marianna Kaimaki's paper, entitled 'Tunes in free variation and sequentially determined pitch alignment: evidence from interactional organization', is a prosodic study of talk-in-interaction in line with work that shows how conversational items can do different interactional work according to their prosodic characteristics (Kelly and Local, 1989; Local, 1996). She points out the intonational differences and interactional environments of response-tosummons turns and other occurrences of the continuer $n e$ in Greek telephone conversations. She underlines the importance of the positioning of such lexical 
items and utterances, and their interactional functions in order to draw conclusions about prosodic organisation.

In his paper on 'Aspects of advice giving and advice receiving in television talk shows,' Apostolos Poulios explores advice giving during Greek realitytelevision talk shows by the show's host/hostess and/or resident professional expert. He also addresses the acceptance or rejection of advice by the guest. His work contributes to CA research on troubles telling and advice (Jefferson and Lee, 1981; Heritage and Sefi, 1992; Hutchby, 1995), underlining the importance of affiliative advice in its subsequent acceptance. On the other hand, guests may also reject the advice proffered when it is hearable as a criticism. This is a detailed analysis of social action as situated in an intermediate type of talk between the mundane and the public domain.

Maria Christodoulidou's article, 'Complaints about misbehaviour,' investigates complaint sequences in Cypriot Greek ordinary conversations among intimates. She shows how participants construct their complaints by expressing a negative moral stance towards a non-present party's misbehaviour, packed together with overly detailed and exaggerated reporting and the quoting of the oppositional conversation that the complainant has had with the opponent. Christodoulidou also locates and studies phenomena of extreme case formulations and exaggerations in the complaint sequences. As in Poulios's work, the importance of social action in the course of the conversation is stressed. Christodoulidou builds on existing CA research on complaints (Drew, 1998; Bergmann, 1998) and further extends it as far as the types of descriptions of transgression and the responses to complaints are concerned. She particularly underlines the affiliative work done in the recipients' responses.

In 'Code alternation patterns in bilingual family conversation: a conversation analysis approach,' Marianthi Georgalidou, Hasan Kaili and Aytac Celtek focus on the organisation of bilingual conversation in talk-in-interaction. More specifically, they look at code alternation between Greek and Turkish with clear discourse functions (following Auer's 1995 and 1998 model). They also examine non-prototypical instances of the use of Greek and Turkish in the same conversation as occasions of either medium negotiation and/or mixedcode choice. Finally, they examine how the choices of speakers from different age groups during interaction can offer insights into issues of identity.

The final article in this collection, 'Closing in on story openings and closings: evidence from conversational stories in Greek' by Alexandra Georgakopoulou, employs CA to analyse storytelling data drawn from a group of female adolescents, building on her own work on narrative analysis but also on the CA study of story openings and closings by Jefferson (1978) and Sacks (1992) respectively. The story openings are launched in a straightforward and quick manner that Georgakopoulou links to the type of stories told and the relationship 
among participants. She introduces the term 'counter stories' to describe the dis-aligning closings which appeared in her data and to mark them out from Sacks's 'second stories'. In line with a CA rationale, Georgakopoulou's work avoids over-generalisation by resisting assuming properties of 'Greekness' in advance in narrative data. At the same time, the author points out the limitations of such an approach and the need for CA to widen its scope so far as the analysis of story endpoints is concerned.

\section{Looking ahead}

Although CA-informed research of Greek conversational data to date has been mainly undertaken by (socio)linguists, interest in Greek CA has been growing among sociologists (especially in the use of CA as a qualitative research tool), psychologists (concerning the analysis of patient-therapist interaction), and communication and education experts (regarding the analysis of news interviews and classroom interaction). Such interest is evident both in the courses offered by these departments as well as in the conferences and seminars organised. Despite this growing interest, translations of 'classic' ethnomethodological and CA work into Greek are few and far in between (Garfinkel, 2003 [1967]; Psathas, 2003 [1972], both translated by A. Michalakis in Kalfopoulos 2003; Clayman and Heritage, 2008 [2002], translated by A. Stamou). The need for more translations and overviews of this work is becoming urgent, as CA is gradually being incorporated into undergraduate and graduate curricula. A dedicated online discussion group, the 'Greek Conversation Analysis (GCA) Forum,' was also launched in 2007 (http://www.hadjidemetriou.com/ GCA_FORUM/Welcome.html).

To reiterate, analysis in CA builds on the premise of 'unmotivated listening', which precludes a priori assuming culture-specific properties in conversational narratives and/or in interaction. This does not mean that conversation analysts cannot bring out the relevance of culture in their data. A fine-grained, turnby-turn analysis can help surface subtle instances of 'procedural consequentiality' where grammar, prosody, and interaction mutually influence each other and create culture- and language-specific environments of turn-taking, speaker transition, repair etc. The fact that a rich CA bibliography on different areas of study already exists in different languages enables Greek researchers to pinpoint and pursue research on important phenomena that can move the crosscultural CA agenda forward.

In closing, we would like to thank the contributors to this special issue who accepted our invitation to produce specially commissioned articles showcasing different aspects of Greek talk-in-interaction. We are also thankful to the 
editors of the Journal of Greek Linguistics who trusted us to produce a highquality issue that we hope will help promote the study of CA in Greece and on Greek. Although still in its infancy, research on Greek CA is promising and is pointing in many directions. Apart from the vast array of topics in the fields of grammar and prosody-in-interaction, the study of institutional settings and multimodality are areas which are still only marginally addressed in Greek data. ${ }^{13}$ As a final word, we would like to stress the distinct need for Greek CA to stay close to its ethnomethodological roots and to situate the study of talk in actual interaction and in social action, beyond a normative framework of conversational rules.

This special issue is dedicated to the memory of Professor Christina Kakava (21 Nov. 1960-20 Feb. 2010) who was a pioneer in the study of verbal interaction among Greeks. Her work continues to be an invaluable source of inspiration.

\section{References}

Antaki, Charles. 2002. An Introductory Tutorial in Conversation Analysis. Available online at http://www-staff.lboro.ac.uk/ ssca1/sitemenu.htm. Date accessed 10/5/2010.

Antaki, Charles and Sue Widdicombe. 1998. Identity as an achievement and as a tool. In C. Antaki and S. Widdicombe (eds.), Identities in Talk, 1-14. London: Sage.

Archakis, Argiris and Ioanna Skarvelaki. 2009. Evó $\rho \xi \varepsilon ı \varsigma ~ \sigma u v o \mu \imath \lambda \iota \alpha \kappa \omega ́ v \alpha \varphi \eta \gamma \eta \dot{\sigma \varepsilon \omega v ~[C o n v e r-~}$ sational narrative openings]. In Proceedings of the $8^{\text {th }}$ International Conference on Greek Linguistics, Ioannina, 30 August-2 September 2007. Available online at http://www.linguist -uoi.gr/cd_web/docs/greek/04_archakisICGL8.pdf., 646-660.

Arminen, Ikka. 2005. Institutional Interaction. Aldershot: Ashgate.

Atkinson, J. Maxwell and Paul Drew. 1979. Order in Court: The Organisation of Verbal Interaction in Judicial Settings. Hampshire and London: Macmillan.

Attardo, Salvatore. 2001. Humorous Texts: A Semantic and Pragmatic Analysis. Berlin: Mouton de Gruyter.

Auer, Peter J. C. 1988. A conversation analytic approach to code-switching and transfer. In M. Heller (ed.), Code-Switching: Anthropological and Sociolinguistic Perspectives, 187-214. Berlin: Mouton de Gruyter.

Auer, Peter. 1995. The pragmatics of code-switching: A sequential approach. In L. Milroy and P. Muysken (eds.), One speaker, Two Languages, 115-135. Cambridge: Cambridge University Press.

Auer, Peter J. C. 1998. Introduction: Bilingual Conversation revisited. In P. Auer (ed.), Code-switching in Conversation: Language, Interaction and Identity, 1-24. London: Routledge.

${ }^{13}$ For a recent analysis of multimodality from a CA perspective, see Koutsombogera and Papageorgiou, 2009. 
Baker, Carolyn. 1997. Membership categorization and interview accounts. In D. Silverman (ed.), Qualitative Research: Theory, Method and Practice, 130-43. London: Sage.

Benwell, Bethan M. and Elizabeth H. Stokoe. 2006. Discourse and Identity. Edinburgh: Edinburgh University Press.

Bergmann, Jörg R. 1998. Introduction: Morality in discourse. Research on Language and Social Interaction 31(3 and 4): 279-94.

Betz, Emma M. 2008. Grammar and Interaction: Pivots in German Conversation. Amsterdam/ Philadelphia: John Benjamins.

Billig, Michael. 1999a. Whose terms? Whose ordinariness? Rhetoric and ideology in Conversation Analysis. Discourse and Society 10: 543-558.

Billig, Michael. 1999b. Conversation Analysis and the claims of naivety. Discourse and Society 10: 572-576.

Bozatzis, Nikolaos. 1999. Greek National Identity in Talk: The Rhetorical Articulation of an Ideological Dilemma. Unpublished PhD Thesis, University of Lancaster, UK. Available online at http://uoi.academia.edu/documents/0092/9984/Greek_National_Identity_in_Talk.pdf. Date accessed 7/4/2010.

Brown, Penelope and Stephen C. Levinson. 1987. Politeness: Some Universals in Language Usage. Cambridge: Cambridge University Press.

Chevalier, Fabienne H. G. 2008. Unfinished turns in French conversation: how context matters. Research on Language and Social Interaction 41: 1-30.

Clayman, Steven and John Heritage. 2008 [2002]. H Eı



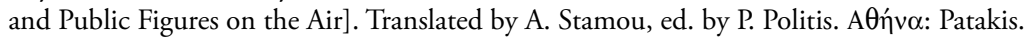

Coulon, Alain. 1995. Ethnomethodology. London: Sage.

Couper-Kuhlen, Elizabeth and Cecilia E. Ford. 2004. Sound Patterns in Interaction. Crosslinguistic Studies from Conversation. Amsterdam/Philadelphia: John Benjamins.

Couper-Kuhlen, Elizabeth and Margaret Selting. 2001. Introducing Interactional Linguistics. In M. Selting and E. Couper-Kuhlen (eds.), Studies in Interactional Linguistics, 1-22. Amsterdam/Philadelphia: John Benjamins.

Drew, Paul. 1998. Complaints about transgression and misconduct. Research on Language and Social Interaction 31 (3 and 4): 295-325.

Drew, Paul and John Heritage. 1992a. (eds.). Talk at Work: Interaction in Institutional Settings. Cambridge: Cambridge University Press.

Drew, Paul and John Heritage. 1992b. Analyzing talk at work: An introduction. In P. Drew and J. Heritage (eds.), Talk at Work: Interaction in Institutional Settings, 3-65. Cambridge: Cambridge University Press.

Drew, Paul, Geoffrey Raymond and Darin Weinberg. 2006. (eds.). Talk and Interaction in Social Research Methods. London: Sage.

Edwards, Derek and Jonathan Potter. 1992. Discursive Psychology. London: Sage.

Egbert, Maria M. 1996. Context sensitivity in conversation analysis: Eye gaze and the German repair initiator "bitte.". Language in Society 25: 587-612.

Fairclough, Norman. 1995. Critical Discourse Analysis: The Critical Study of Language. London: Longman.

Fox, Barbara A., Makoto Hayashi and Robert Jasperson. 1996. Resources and repair: a crosslinguistic study of syntax and repair. In E. Ochs, E. A. Schegloff and S. A. Thompson (eds.), Interaction and Grammar, 183-237. Cambridge: Cambridge University Press.

Garfinkel, Harold. 1967. Studies in Ethnomethodology. Cambridge: Polity Press.

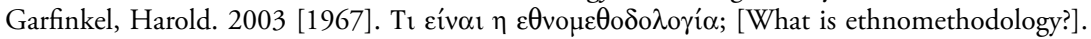
Translated by A. Michalakis in K. Kalfopoulos (ed.), HПoı

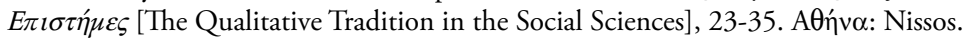


Garfinkel, Harold and Harvey Sacks. 1970. On formal structures of practical actions. In J. C. McKinney and E. A. Tiryakian (eds.), Theoretical Sociology: Perspectives and Developments, 337-366. New York, NY: Appleton-Century-Crofts.

Georgakopoulou, Alexandra. 2006. The other side of the story: towards a narrative analysis of narratives-in-interaction. Discourse Studies 8: 235-257.

Gilbert, Nigel and Michael Joseph Mulkay. 1984. Opening Pandora's Box: A Sociological Analysis of Scientists' Discourse. Cambridge: Cambridge University Press.

Goffman, Erving. 1983. The Interaction Order. American Sociological Review 48: 1-17.

Goodwin, Charles. 2000. Practices of seeing: Visual analysis - an ethnomethodological approach. In T. v. Leeuwen and C. Jewitt (eds.), Handbook of Visual Analysis, 157-182. London: Sage.

Goodwin, Charles. 2003a. (ed.). Conversation and Brain Damage. Oxford: Oxford University Press.

Goodwin, Charles. 2003b. Conversational frameworks for the accomplishment of meaning in aphasia. In C. Goodwin (ed.), Conversation and Brain Damage, 90-116. Oxford: Oxford University Press.

Gumperz, John. 1982. Discourse Strategies. London: Cambridge University Press.

Hadjidemetriou, Chryso. 2001. Self-initiated Self-repairs and Syntax-for-Interaction: Evidence from Greek Conversation. Unpublished MA Thesis, University of Essex, UK.

Hayashi, Makoto. 2003. Joint Utterance Completion in Japanese Conversation. Amsterdam/ Philadelphia: John Benjamins.

Heritage, John. 1984. Garfinkel and Ethnomethodology. Cambridge: Polity Press.

Heritage, John. 1995. Conversation Analysis: Methodological aspects. In U.M. Quasthoff (ed.), Aspects of Oral Communication, 391-418. Berlin: Walton de Gruyter.

Heritage, John. 1997. Conversation Analysis and institutional talk. In D. Silverman (ed.), Qualitative Research: Theory, Method and Practice, 161-182. London: Sage.

Heritage, John and Sue Sefi. 1992. Dilemmas of advice: Aspects of the delivery and reception of advice in interactions between health visitors and first-time mothers. In P. Drew and J. Heritage (eds.), Talk at Work, 359-417. Cambridge: Cambridge University Press.

Houtkoop-Steenstra, Hanneke. 1991. Opening sequences in Dutch telephone conversations. In D. Boden and D.H. Zimmerman (ed.), Talk and Social Structure. Studies in Ethnomethodology and Conversation Analysis, 232-252. Cambridge: Polity Press.

Hutchby, Ian. 1995. Aspects of recipient design in expert advice giving on call in radio. Discourse Processes 19: 219-38.

Hutchby, Ian. 1999. Beyond agnosticism? Conversation Analysis and the sociological agenda. Research on Language and Social Interaction 32 (1 \& 2): 85-93.

Hutchby, Ian. 2001. Conversation and Technology: From the Telephone to the Internet. Cambridge: Polity Press.

Hutchby, Ian and Simone Barnett. 2005. Aspects of the sequential organisation of mobile phone conversation. Discourse Studies 7: 147-71.

Hutchby, Ian and Robin Wooffitt. 2008. ( $2^{\text {nd }}$ edition) Conversation Analysis: Principles, Practices and Applications. Cambridge: Polity Press.

Jefferson, Gail. 1978. Sequential aspects of storytelling in conversation. In J. Schenkein (ed.), Studies in the Organisation of Conversational Interaction, 219-249. New York: Academic Press.

Jefferson, Gail. 1989. Preliminary notes on a possible metric which provides for a "standard maximum" silence of approximately one second in conversation. In D. Roger and P. Bull (eds.), Conversation: An Interdisciplinary Perspective, 166-196. Clevedon: Multilingual Matters.

Jefferson, Gail. 2004. Glossary of transcript symbols with an introduction. In G.H. Lerner (ed.), Conversation Analysis: Studies from the First Generation, 13-31. Amsterdam/Philadelphia: John Benjamins. 
Jefferson, Gail and John R. E. Lee. 1981. The rejection of advice: Managing the problematic convergence of a "troubles telling" and a "service encounter". In P. Drew and J. Heritage (eds.), Talk at Work, 521-548. Cambridge: Cambridge University Press.

Kaimaki, Marianna. 2009. Phonetic Resources and Interactional Function in English and Greek conversation: Variation and Constraints. Unpublished PhD Thesis, University of York, UK.

Kelly, John and John K. Local 1989. On the use of general phonetic techniques in handling conversational material. In D. Roger and P. Bull (eds.), Conversation: An Interdisciplinary Perspective. Clevedon: Multilingual Matters: 197-212.

Kim, Kyu-hyun. 1999. Other-initiated repair sequences in Korean conversation. Discourse and Cognition 6: 141-168.

Kitzinger, Celia. 2000. Doing Feminist Conversation Analysis. Feminism and Psychology 10: 163-193.

Koutsombogera Maria and Harris Papageorgiou. 2009. Multimodality issues in Conversation Analysis of Greek TV interviews. In A. Esposito, A. Hussain, M. Marinaro and R. Martone (eds.), Multimodal Signals: Cognitive and Algorithmic Issues. Lecture Notes in Artificial Intelligence, 5398: 40-46, Springer-Verlag, Berlin Heidelberg.

Labov, William. 1970. The study of language in its social context. Studium Generale 23: 30-87.

Labov, William. 1972. Sociolinguistic Patterns. Philadelphia, PA: University of Pennsylvania Press.

Local, John. 1996. Conversational phonetics: some aspects of news receipts in everyday talk. In E. Couper-Kuhlen and M. Selting (eds.), Prosody in Conversation: Interactional Studies, 177-230. Cambridge: Cambridge University Press.

Luff, Paul and Christian Heath. 2002. Broadcast talk: Technologically mediated action in a complex setting. Research on Language and Social Interaction 35: 337-66.

Luff, Paul, Jon Hindmarsh and Christian Heath, 2000. (eds.). Workplace Studies: Recovering Work Practice and Informing Systems Design. Cambridge: Cambridge University Press.

Makri-Tsilipakou, Marianthi. 1994. Interruption revisited: Affiliative vs disaffiliative intervention. Journal of Pragmatics 21: 401-426.

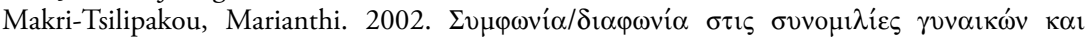
$\alpha v \delta \rho \omega ́ v$ [Agreement/disagreement: Affiliative vs. disaffiliative display in cross-sex conversations]. In Th. Pavlidou (ed.), $\Gamma \lambda \omega ́ \sigma \sigma \alpha, \Gamma \varepsilon ́ v o \varsigma, \Phi v ́ \lambda o$ [Language, Gender, Sex], 97-144.

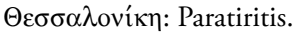

Makri-Tsilipakou, Marianthi. 2003. Greek diminutive use problematised: Gender, culture and common sense. Discourse and Society 14: 699-726.

McHoul, Alec. 1978. The organization of turns at formal talk in the classroom. Language in Society 7: 183-213.

McHoul, Alec, Mark Rapley and Charles Antaki. 2008. You Gotta Light? On the luxury of context for understanding talk in interaction. Journal of Pragmatics 40: 827-839.

Mondada, Lorenza. 1995. Formes Linguistiques et Dynamiques Interactionnelles [Linguistic Forms and Interactional Dynamics], Cahiers de l'ILSL7, University of Lausanne.

Mondada, Lorenza. 2007. Multimodal resources for turn-taking: pointing and the emergence of possible next speakers. Discourse Studies 9: 194-225.

Nevile, Maurice. 2004. Beyond the Black Box: Talk-in-Interaction in the Airline Cockpit. Aldershot: Ashgate.

Nofsinger, Robert. E. 1991. Everyday Conversation. London: Sage.

Pavlidou, Theodossia-Soula. 2002. Moving towards closing: Greek telephone calls between familiars. In K.K. Luke and Th.-S. Pavlidou (ed.), Telephone Calls: Unity and Diversity in Conversational Structure across Languages and Cultures, 201-228. Amsterdam/Philadelphia: John Benjamins. 
Petraki, Eleni, Carolyn Baker and Mike Emmison. 2007. "Moral versions" of motherhood and daughterhood in Greek-Australian family narratives. In M. Bamberg, A. De Fina and D. Schriffrin (eds.), Selves and Identities in Narrative and Discourse, 107-132. Amsterdam/ Philadelphia: John Benjamins.

Pomerantz, Anita. 1984. Agreeing and disagreeing with assessments: Some features of preferred/ dispreferred turn shapes. In M. Atkinson and J. Heritage (eds.), Structures of Social Action: Studies in Conversation Analysis, 57-101. Cambridge: Cambridge University Press and Editions de la Maison des Sciences de l'Homme.

Poulios, Apostolos. 2004. The construction of elderly identity through troubles-telling in Greek conversations. Proceedings of the 6th International Conference of Greek Linguistics, Linguistics Lab, University of Crete. Available online at http://www.philology.uoc.gr/ conferences/6thICGL/. Date accessed 10/5/2010.

Poulios, Apostolos. 2009. Age categories as an argumentative resource in conflict talk: Evidence from a Greek television reality show. International Journal of the Sociology of Language 200: 189-208.

Poulios, Apostolos. In press. Aging actresses/actors in Greece: "Let's (Not) Talk About Age". In A. Swinnen and J. A Stotesbury (eds.), Aging, Performance, and Stardom. Doing Age on the Stage of Consumerist Culture. Berlin: LIT Verlag.






Nissos.

Rossano, Federico. 2005. When it's over is it really over? On the effects of sustained gaze vs. gaze withdrawal at sequence possible completion. Paper presented at the International Pragmatic Association, Riva del Garda, July.

Sacks, Harvey. 1972. On the analyzability of stories by children. In J.J. Gumperz and D. Hymes (ed.), Directions in Sociolinguistics: The Ethnography of Communication, 325-345. New York: Rinehart and Winston.

Sacks, Harvey. 1979. Hotrodder: a revolutionary category. In G. Psathas (ed.), Everyday Language: Studies in Ethnomethodology, 7-14. New York: Irvington.

Sacks, Harvey. 1984. Notes on Methodology. In M. Atkinson and J. Heritage (Eds.), Structures of Social Action: Studies in Conversation Analysis, 21-27. Cambridge: Cambridge University Press and Editions de la Maison des Sciences de l'Homme.

Sacks, Harvey. 1992. Lectures in Conversation, 2 vols., edited by G. Jefferson, Oxford: Basil Blackwell.

Sacks, Harvey, Emanuel. A. Schegloff, and Gail Jefferson. 1974. A simplest systematics for the organisation of turn-taking for conversation. Language 50: 696-735.

Sarangi, Srikant and Celia Roberts. 1999. (eds.). Talk, Work, and Institutional Order: Discourse in Medical, Mediation, and Management Settings. Berlin: Mouton de Gruyter.

Schegloff, Emanuel A. 1968. Sequencing in conversational openings. American Anthropologist 70: 1075-1095.

Schegloff, Emanuel A. 1987a. Analyzing single episodes of interaction: An exercise in Conversation Analysis. Social Psychology Quarterly 50: 101-114.

Schegloff, Emanuel A. 1987b. Between micro and macro: Contexts and other connections. In J.C. Alexander, B. Giesen, R. Münch and N.J. Smelser (eds.), The Micro-Macro Link, 207-234. Berkeley and Los Angeles: University of California Press.

Schegloff, Emanuel A. 1988. Goffman and the analysis of conversation. In P. Drew and A. Wootton (eds.), Erving Goffman: Exploring the Interaction Order, 89-135. Cambridge: Polity Press. 
Schegloff, Emanuel A. 1991. Reflections on talk and social structure. In D. Boden and D. H. Zimmerman (eds.), Talk and Social Structure: Studies in Ethnomethodology and Conversation Analysis, 44-71. Cambridge: Polity Press.

Schegloff, Emanuel A. 1996. Confirming allusions: Toward an empirical account of action. American Journal of Sociology 102: 161-216.

Schegloff, Emanuel A. 1997. "Narrative Analysis" thirty years later. Journal of Narrative and Life History 7: 97-106.

Schegloff, Emanuel A. 1998a. Reply to Wetherell. Discourse and Society 9: 413-416.

Schegloff, Emanuel A. 1998b. Reflections on studying prosody in talk-in-interaction. Language and Speech 41: 235-263.

Schegloff, Emanuel A. 1999a. Schegloff's texts as 'Billig's data': A critical reply. Discourse and Society 10: 558-572.

Schegloff, Emanuel 1999b. Naivete vs sophistication or discipline vs self-indulgence: A rejoinder to Billig. Discourse and Society 10: 577-582.

Schegloff, Emanuel A. 2007a. Sequence Organization in Interaction. Cambridge: Cambridge University Press.

Schegloff, Emanuel A. 2007b. A tutorial on membership categorization. Journal of Pragmatics 39: 462-482.

Schegloff, Emanuel A. 2009. One perspective on Conversation Analysis: Comparative Perspectives. In J. Sidnell (ed.), Conversation Analysis: Comparative Perspectives, 357-406. Cambridge: Cambridge University Press.

Schegloff, Emanuel A., Gail Jefferson and Harvey Sacks. 1977. The preference for self-correction in the organization of repair in conversation. Language 53: 361-382.

Schegloff, Emanuel A., Elinor Ochs and Sandra A. Thompson. 1996. Introduction. In E. Ochs, E. A. Schegloff and S. A. Thompson (eds.), Interaction and Grammar, 1-51. Cambridge: Cambridge University Press.

Schegloff, Emanuel A. and Harvey Sacks, 1973. Opening up closings. Semiotica 8: 289-327.

Seedhouse, Paul. 2004. The Interactional Architecture of the Language Classroom: A Conversation Analysis Perspective. Malden, MA: Blackwell.

Sidnell, Jack. 2009a. (ed.). Conversation Analysis: Comparative Perspectives, Cambridge: Cambridge University Press.

Sidnell, Jack. 2009b. Comparative perspectives in Conversation Analysis. In J. Sidnell (ed.), Conversation Analysis: Comparative Perspectives, Cambridge: Cambridge University Press.

Sifianou, Maria. 2002. On the telephone again! Telephone call openings in Greek. In K.K. Luke and Th.-S. Pavlidou (eds.), Telephone Calls: Unity and Diversity in Conversational Structure across Languages and Cultures, 49-85. Amsterdam/Philadelphia: John Benjamins.

Silverman, David. 1999. Warriors or collaborators: Reworking methodological controversies in the study of institutional interaction. In S. Sarangi and C. Roberts (eds.), Talk, Work, and Institutional Order: Discourse in Medical, Mediation, and Management Settings, 401-425. Berlin: Mouton de Gruyter.

Silverman, David. 2006. (3 ${ }^{\text {rd }}$ edition). Interpreting Qualitative Data: Methods for Analyzing Talk, Text and Interaction. London: Sage.

Sinclair, John McHardy and Malcolm Coulthard. 1975. Towards an Analysis of Discourse: The English Used by Teachers and Pupils. Oxford: Oxford University Press.

Sorjonen, Marja-Leena. 1996. On repeats and responses in Finnish conversation. In E. Ochs, E.A. Schegloff and S.A. Thompson (eds.), Interaction and Grammar, 277-327. Cambridge: Cambridge University Press.

Speer, Susan. 2005. Gender Talk: Feminism, Discourse and Conversation Analysis. London: Routledge. 
Stokoe, Elizabeth H. and Janet Smithson. 2001. Making gender relevant: conversation analysis and gender categories in interaction. Discourse and Society 12: 217-244.

Suchman, Lucy. 1987. Plans and Situated Actions. Cambridge: Cambridge University Press.

Tanaka, Hiroko. 1999. Turn-Taking in Japanese Conversation: A Study in Grammar and Interaction. Amsterdam/Philadelphia: John Benjamins.

Te Molder, Hedwig and Jonathan Potter. 2005. (eds.). Conversation and Cognition. Cambridge: Cambridge University Press.

ten Have, Paul. 1999. Doing Conversation Analysis: A Practical Guide. London: Sage.

Terkourafi, Marina. 2009. 'Emic/Etic.' In S. Chapman and C. Routledge (eds.). Key Ideas in Linguistics and the Philosophy of Language, 66. Edinburgh: Edinburgh University Press.

Tzanne, Angeliki. 2000. Talking at Cross-Purposes: The Dynamics of Miscommunication. Amsterdam/Philadelphia: Benjamins.

van Dijk, Teun A. 1999. Editorial: Critical Discourse Analysis and Conversation Analysis. Discourse and Society 10: 459-460.

van Dijk, Teun A. 2006. Introduction: Discourse, interaction and cognition. Discourse Studies 8: 5-7.

Vasilopoulou, Alexandra. 2005. Socialisation Through Talk: A study of Greek Nursery Classroom Interaction. Nissos Academic Publishing 1, A $\theta$ ńvo: Nissos.

Vasilopoulou, Alexandra. 2006. Pupils' methods in the nursery classroom: A basis for socialisation and learning?. International Journal of Learning 12: 113-122.

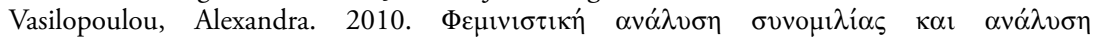


conversation analysis and membership categorization analysis: two approaches for the

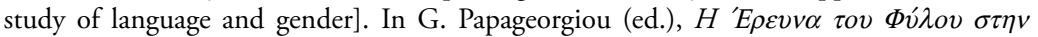
$E \lambda \lambda \alpha \dot{\alpha} \delta \alpha[$ Gender research in Greece], 145-165. A $\theta \dot{v} v \alpha$ : Gutenberg.

Whalen, Marilyn R., Jack Whalen, Robert J. Moore, Geoffrey Raymond, Margaret Szymanski and Erik Vinkhuyzen. 2004. Studying workscapes as a natural observational discipline. In P. LeVine and R. Scollon (eds.), Discourse and Technology: Multimodal Discourse Analysis, 109-129. Washington, DC: Georgetown University Press.

Wilkinson, Ray. 1995. Aphasia: conversation analysis of a non-fluent aphasic person. In: M. Perkins and S. Howard (eds.), Case Studies In Clinical Linguistics, 271-292. London: Whurr.

Wilkinson, Ray. 1999. Sequentiality as a problem and resource for intersubjectivity in aphasic conversation: analysis and implications for therapy. Aphasiology 13: 327-343.

Wei, Li. 2005. Starting from the right place: introduction to the special issue on Conversational Code-Switching. Journal of Pragmatics 37: 275-279.

Wetherell, Margaret. 1998. Positioning and interpretative repertoires: conversation analysis and post-structuralism in dialogue. Discourse and Society 9: 387-412.

Wooffitt, Robin. 2005. Conversation Analysis and Discourse Analysis: A Comparative and Critical Introduction. London: Sage.

Wootton, Anthony J. 2002/2003. Interactional contrasts between typically developing children and those with autism, Asperger's Syndrome, and pragmatic impairment. Issues in Applied Linguistics 13: 133-160. 
